\title{
Study the Effect of Spironolactone in Airway Resistance with Impulse Oscillometry in Patients with Congestive Heart Failure
}

\author{
Yousef Gholampour ${ }^{1}$, Mohammad Nourizadeh ${ }^{1}$, Mohammad Hasan Adel ${ }^{*}$, Esmaeel Eidani' \\ Ahmad Amin', Mahsa Asadimoghadam³, Mehdi Nourizadeh1, Sara Nourizadeh ${ }^{4}$ \\ ${ }^{1}$ Cardiovascular Disease Research Center, Ahvaz Jundishapur University of Medical Sciences, Ahvaz, Iran \\ ${ }^{2}$ Respiratory Ward, Imam Khomeini Hospital, Ahvaz Jundishapur University of Medical Sciences, Ahvaz, Iran \\ ${ }^{3}$ Heart Failure Department, Shaheed Rajaee Hospital, Iran University Medical Sciences, Tehran, Iran \\ ${ }^{4}$ Department of Cell \& Molecular Biology, Faculty of Biological Sciences, Kharazmi University, Tehran, Iran \\ Email: ${ }^{*}$ r.hassan.adel@gmail.com
}

How to cite this paper: Gholampour, Y., Nourizadeh, M., Adel, M.H., Eidani, E., Amin, A., Asadimoghadam, M., Nourizadeh, M. and Nourizadeh, S. (2018) Study the Effect of Spironolactone in Airway Resistance with Impulse Oscillometry in Patients with Congestive Heart Failure. Health, 10, 691-699.

https://doi.org/10.4236/health.2018.105053

Received: April 3, 2018

Accepted: May 27, 2018

Published: May 30, 2018

Copyright () 2018 by authors and Scientific Research Publishing Inc. This work is licensed under the Creative Commons Attribution International License (CC BY 4.0).

http://creativecommons.org/licenses/by/4.0/ (c) (i) Open Access

\begin{abstract}
Background: CHF (Congestive Heart Failure) is one of the most important causes of mortality and morbidity in the world. Diuretics such as spironolactone can decrease pulmonary congestion and reduce the amount of fibrosis in CHF patients. The goal was to assess whether spironolactone can decrease air way resistance and can we follow up the effect of diuretic therapy in patients of heart failure quantitatively by means of impulse oscillometry. Methods: It was clinical trial which performed in Ahvaz teaching hospital. 24 patients with congestive heart failure (CHF) which was classified as functional class II-IV and had $\mathrm{EF}<40 \%$, were assessed by impulse oscillometry before and after 1 month of taking spironolactone in addition to routine drug therapy for their symptoms. All data were analyzed by SPSS soft ware versed 16. Result: The age of patient was $61 \pm 10$ and the age of control was $57 \pm 7$ years old. The data of oscillometry before and after spironolactone were X5 $(-0.14 \pm 0.05$ vs $-0.14 \pm 0.05, P$ : 0.93), R5 ( $0.39 \pm 0.21$ vs $0.39 \pm 0.15, P$ : 0.35$), \mathrm{X} 20(-0.04 \pm$ 0.06 vs $-0.06 \pm 0.06, P$ : 0.37 ), R20 (0.04 \pm 0.03 vs $0.06 \pm 0.06, P$ : 0.37 ), Zrs $(0.39 \pm 0.21$ vs $0.39 \pm 0.15, P .0 .35)$. Conclusion: There was a trend toward reduction of peripheral airway resistances in $\mathrm{CHF}$ patients than controls with use of 1 month of spironolactone. Although there was not significant change in the number of X5, R5, X20, R20 occurred the trend toward reduction of number triggers the point that oscillometry can be used for quantitative follow up of CHF patients.
\end{abstract}

\section{Keywords}

Spironolactone, Oscillometry, Congestive Heart Failure 


\section{Introduction}

CHF (congestive heart failure) is one of the most leading causes of death worldwide. With more than 20 million people affected, the overall prevalence of HF in the adult population in developed countries is $2 \%$. HF prevalence follows an exponential pattern, rising with age, and it affects $6 \%-10 \%$ of people over the age of 65 .

The cardinal symptoms of HF are fatigue and shortness of breath. Heart failure is the pathophysiologic state in which the heart, via an abnormality of cardiac function (detectable or not), fails to pump blood at a rate commensurate with the requirements of the metabolizing tissues or is able to do so only with an elevated diastolic filling pressure [1] [2].

The most important mechanism is pulmonary congestion with accumulation of interstitial or intra-alveolar fluid. Other factors that contribute to dyspnea during exercising include reductions in pulmonary compliance, increased airway resistance, respiratory muscle and/or diaphragm fatigue and anemia [3] [4].

Because of lung congestion in patients with heart failure the volume and resistance of them is changing, assessment of respiratory function is important in diagnosis and monitoring of patients with heart failure and other respiratory diseases [4]. The pulmonary function test most commonly used to detect small airway impairment and asthma is spirometry, which measures the volume of air that can be moved in or out of the lungs as a function of time with rapid and maximal inspiratory and expiratory efforts. This requires a considerable degree of cooperation from the subject that makes the diagnosis of functional capacity of the lungs difficult owing to the lack of objective measurements for old or unconscious patients. In contrast to forced spirometry, Forced Oscillation Technique (FOT) superimposes small air pressure perturbations on the natural breathing of a subject to measure the mechanical properties of the lungs. The Impulse Oscillometry System (IOS) uses this technique and measures respiratory impedance using short pulses (impulses) of air pressure. Impulse oscillometry has been developed as a patient-friendly lung function test that minimizes demands on the patient and requires only passive cooperation of the subject [5]. Furthermore, it has been reported that some CHF patients do not improve spirometrically, despite clinical improvement with treatment [6].

Mineralocorticoids, such as aldosterone, cause retention of salt and water and increase the excretion of $\mathrm{K}^{+}$and $\mathrm{H}^{+}$by binding to specific mineralocorticoid receptors. Because the level of aldosterone in patients with heart failure is high and it leads to fluid accumulations and fibrosis of the lungs, we hypothesis that spironolactone by antagonizing the effect of aldosterone may reduce pulmonary resistance. So we evaluate the effect of spironolactone in airway resistance with impulse oscillometry in patients with CHF.

Although CHF is one of the most problems of health in the world we usually don't have special device to assess the efficacy of drug treatment precisely. We usually evaluate patients with heart failure by using New York heart association 
criteria which is based on patients symptoms that may not precise enough for evaluating the effect of drugs and progress of improvement.

So in this study we evaluated the effect of spironolactone of airway resistance and sought whether it can be used as a device for follow up of CHF patients.

\section{Patients and Methods}

This was a clinical trial study conducted in Imam Hospital in Ahwaz Jundishapur University in May to July 2011. We performed impulse oscillometry on 24 patients with CHF. The study was approved by the local ethics Committee of Ahvaz Jundishapour university research center and informed consent was given to all patients. CHF was defined as the presence of symptoms of fatigue or shortness of breath on exertion and a left ventricular ejection fraction on echocardiography of less than $40 \%$ with no other cause of dyspnea.

Inclusion criteria for patients were CHF patients that were classified according to NYHA class (New York Heart Association) II-IV (Table 1).

The Criteria Committee of the New York Heart Association. Nomenclature and Criteria for Diagnosis of Diseases of the Heart and Great Vessels. 9th ed. Boston, Mass: Little, Brown \& Co.; 1994: 253-256 and all of our patients were taken beta blocker and ACE (Angiotensin Converting Enzyme) inhibitor. Furosemide were used by 8 persons who had congestion in physical examination, none of our patients were taken spironolactone before.

Exclusion criteria for patients were previous diagnosis of chest disease, or symptoms and signs suggestive of primary chest disease and those with an FEV1 less than $75 \%$ predicted. All patients had no evidence of primary lung pathology on a chest radiograph within the one year ago. We also excluded patients with neurologic conditions possibly affecting pulmonary function or inducible ischemia on exercise. Current smoking can increase airway resistance [7] [8] [9]. We therefore excluded current or recent ( $<6$ months) smokers.

The controls were of a similar age chosen randomly. None of the controls were on regular medication and had not visited their general practitioner in the preceding 24 months. Subjects underwent echocardiography to exclude left ventricular dysfunction.

Selected patients were evaluated with spirometry and oscillometry by using the Impulse oscillometry instrument, JAEGER model, made in Germany. Impulse oscillometry measures airway resistance by sending a sound wave produced by a loudspeaker into the lungs of a spontaneously breathing subject and then collecting the reflection of the wave. The reflected wave will vary in amplitude and phase according to the resistance and reactance of the lungs. By applying repeated sound waves of varying frequencies and at different phases of the respiratory cycle, the instrument can measure airway resistance of the respiratory tree at different levels. Resistances of central and peripheral airways are shown by $R_{20}, R_{5}$. Reactance (X), in this context, consists of the capacity of the respiratory system (its elasticity) and the inertia of the column of air in the respiratory tree. Central and peripheral reactance is shown by $\mathrm{X}_{20}, \mathrm{X}_{5}$ [10] [11]. 
Table 1. NYHA functional classification.

\begin{tabular}{|c|c|}
\hline NYHA Class & Patients with Cardiac Disease (Description of HF Related Symptoms) \\
\hline Class I (Mild) & $\begin{array}{l}\text { Patients with cardiac disease but without resulting in limitation of physical } \\
\text { activity. Ordinary physical activity does not cause undue fatigue, palpitation } \\
\text { (rapid or pounding heart beat), dyspnea (shortness of breath), or anginal pain } \\
\text { (chest pain). }\end{array}$ \\
\hline Class II (Mild) & $\begin{array}{l}\text { Patients with cardiac disease resulting in slight limitation of physical activity. } \\
\text { They are comfortable at rest. Ordinary physical activity results in fatigue, } \\
\text { palpitation, dyspnea, or anginal pain }\end{array}$ \\
\hline Class III (Moderate) & $\begin{array}{l}\text { Patients with cardiac disease resulting in marked limitation of physical } \\
\text { activity. They are comfortable at rest. Less than ordinary activity causes } \\
\text { fatigue, palpitation, dyspnea, or anginal pain. }\end{array}$ \\
\hline Class IV (Severe) & $\begin{array}{l}\text { Patients with cardiac disease resulting in the inability to carry on any physical } \\
\text { activity without discomfort. Symptoms of heart failure or the anginal } \\
\text { syndrome may be present even at rest. If any physical activity is undertaken, } \\
\text { discomfort is increased. }\end{array}$ \\
\hline
\end{tabular}

The resistive component of IOS parameters $(\mathrm{R})$ mainly reflects the frictional loss occurring during airflow in the bronchus, while the non-resistive component of IOS parameters $(\mathrm{X})$ reflects the energy which mostly stored by peripheral parts of the respiratory system.

Spironolactone $25 \mathrm{mg}$ were given to all of our patients from function class II-IV for 1 month. Then they evaluated again by using IOS one month later.

Results are reported as means (standard deviations). We used unpaired student $\mathrm{t}$-test for inter-groups comparisons and paired $\mathrm{t}$-test for intra-group analysis. $P$ value less than 0.05 was regarding significant.

\section{Results}

The age of patient was $61 \pm 10$ and the age of control was $57 \pm 7$ years old. As shown in Table 2 the patients and control were matched regarding age, weight and gender.

The most prevalent sign between CHF patients was ischemia in EKG and Cardiomegaly in CXR.

Control patients had higher FEV1 and FVC and lower R5 and R20 (Table 3).

Before taking spironolactone the more correlation between IOS data and spirometry took place at R5 (Table 4).

After taking spironolactone FEV1 and FVC increased and R5 and Zr5 decreased but there were not significant (Table 5).

The data of oscillometry before and after spironolactone were $\mathrm{X}_{5}(-0.14 \pm 0.05$ vs $-0.14 \pm 0.05, P$ : 0.93$), \mathrm{R}_{5}(0.39 \pm 0.21$ vs $0.39 \pm 0.15, P: 0.35), \mathrm{X}_{20}(-0.04 \pm 0.06$ vs $-0.06 \pm 0.06, P: 0.37), \mathrm{R}_{20}(0.04 \pm 0.03$ vs $0.06 \pm 0.06, P: 0.37), \mathrm{Z}_{\mathrm{rs}}(0.39 \pm 0.21$ vs $0.39 \pm 0.15, P .0 .35$ ) (Table 5).

Although it was a trend toward reduction of oscillometry numbers they were not significant. 
Table 2. Basic characteristics of subjects.

\begin{tabular}{|c|c|c|c|}
\hline & Patients $(n=24)$ & Controls $(n=24)$ & $P$ value \\
\hline Age $(y)$ & $61 \pm 10$ & $57 \pm 7$ & 0.6 \\
\hline Height $(\mathrm{cm})$ & $166 \pm 9$ & $167 \pm 10$ & 0.9 \\
\hline Weight (kg) & $71 \pm 11$ & $68 \pm 9$ & 0.54 \\
\hline Male & $17(71 \%)$ & $13(54 \%)$ & $>0.05$ \\
\hline FEMALE & $7(29 \%)$ & $11(46 \%)$ & $>0.05$ \\
\hline Smokers & $10(41 \%)$ & $2(8 \%)$ & $<0.05$ \\
\hline Hypertension & $7(29 \%)$ & $2(8 \%)$ & $<0.05$ \\
\hline Diabetes Mellitus & $10(41 \%)$ & $3(12.5 \%)$ & $<0.05$ \\
\hline Old MI & $7(29 \%)$ & & \\
\hline Rales & $10(41 \%)$ & & \\
\hline Ischemia in ECG & $24(100 \%)$ & & \\
\hline Cardiomegaly in CXR & $21(87.5 \%)$ & & \\
\hline Elevated JVP & $14(58.3 \%)$ & & \\
\hline Pulmonary Congestion & $14(58.3 \%)$ & & \\
\hline I & 0 & & \\
\hline \multirow{2}{*}{$\begin{array}{l}\text { NYHA } \\
\text { functional } \\
\text { class }\end{array}$} & $15(62.5 \%)$ & & \\
\hline & $7(29.1 \%)$ & & \\
\hline IV & $2(8.4 \%)$ & & \\
\hline Heart rhythm in ECG & NL: 22 (91.6\%) & & \\
\hline Arrhythmia & $2(8.4 \%)$ & & \\
\hline
\end{tabular}

Values are means percent; MI: Myocardial Infarction; NYHA: New York Heart Association; EKG: Electrocardiography.

Table 3. Spirometry and impulse oscillometry findings in patients and control groups before taking spironolactone.

\begin{tabular}{cccc}
\hline & Patients $(\mathbf{n}=\mathbf{2 4})$ & Controls $(\mathbf{n}=\mathbf{2 4})$ & P value \\
\hline $\mathrm{FEV}_{1}(\mathrm{~L} / \mathrm{min})$ & $2.26 \pm 0.68$ & $3.09 \pm 0.82$ & $\mathbf{0 . 0 1}$ \\
$\mathrm{FVC}(\mathrm{L})$ & $2.55 \pm 0.86$ & $3.32 \pm 0.87$ & $\mathbf{0 . 0 4}$ \\
$\mathrm{R}_{5} \mathrm{~Hz}(\mathrm{kPa} /(\mathrm{L} / \mathrm{s}))$ & $0.37 \pm 0.21$ & $0.27 \pm 0.09$ & $\mathbf{0 . 0 6}$ \\
$\mathrm{R}_{20} \mathrm{~Hz}(\mathrm{kPa} /(\mathrm{L} / \mathrm{s}))$ & $0.26 \pm 0.10$ & $0.24 \pm 0.08$ & $\mathbf{0 . 3 9}$ \\
$\mathrm{X}_{5} \mathrm{~Hz}(\mathrm{kPa} /(\mathrm{L} / \mathrm{s}))$ & $-0.20 \pm 0.13$ & $-0.13 \pm 0.08$ & $\mathbf{0 . 0 5}$ \\
$\mathrm{X}_{20} \mathrm{~Hz}(\mathrm{kPa} /(\mathrm{L} / \mathrm{s}))$ & $-0.04 \pm 0.02$ & $-0.04 \pm 0.02$ & $\mathbf{0 . 2 8}$ \\
$\mathrm{Z}(\mathrm{kPa} /(\mathrm{L} / \mathrm{s}))$ & $0.43 \pm 0.22$ & $0.31 \pm 0.09$ & $\mathbf{0 . 0 3}$ \\
\hline
\end{tabular}

Values are means $\pm \mathrm{SDFEV}_{1}$, forced expiratory volume in the first second; FVC: forced vital capacity; $\mathrm{R}_{5} \mathrm{~Hz}$ : resistance at $5 \mathrm{~Hz} ; \mathrm{R}_{20} \mathrm{~Hz}$ : resistance at $20 \mathrm{~Hz} ; \mathrm{X}_{5} \mathrm{~Hz}$ : reactance at $5 \mathrm{~Hz} ; \mathrm{X}_{20} \mathrm{~Hz}$ : reactance at $20 \mathrm{~Hz}$; Z: impedance of the respiratory system. 
Table 4. Correlation between spirometry and IOS in patients and controls.

\begin{tabular}{ccc}
\hline & $\mathrm{FEV}_{1}(\mathrm{~L} / \mathrm{min})$ & FVC $(\mathrm{L})$ \\
\hline $\mathrm{R} 5 \mathrm{~Hz}(\mathrm{kPa} /(\mathrm{L} / \mathrm{s}))$ & -0.32 & 0.29 \\
$\mathrm{R} 2 \mathrm{O} \mathrm{Hz}(\mathrm{kPa} /(\mathrm{L} / \mathrm{s}))$ & -0.17 & 0.23 \\
$\mathrm{X} 5 \mathrm{~Hz}(\mathrm{kPa} /(\mathrm{L} / \mathrm{s}))$ & $0.60^{*}$ & $0.64^{*}$ \\
$\mathrm{X} 2 \mathrm{O} \mathrm{Hz}(\mathrm{kPa} /(\mathrm{L} / \mathrm{s}))$ & 0.33 & 0.34 \\
$\mathrm{Z}(\mathrm{kPa} /(\mathrm{L} / \mathrm{s}))$ & $0.43^{*}$ & 0.43 \\
\hline
\end{tabular}

$\mathrm{FEV}_{1}$, forced expiratory volume in the first second; $\mathrm{FVC}$, forced vital capacity ; $\mathrm{R} \mathrm{Hz}$, resistance at $5 \mathrm{~Hz} ; \mathrm{R}$ $20 \mathrm{~Hz}$, resistance at $20 \mathrm{~Hz} ; \mathrm{X} 5 \mathrm{~Hz}$, reactance at $5 \mathrm{~Hz} ; \mathrm{X} 2 \mathrm{O} \mathrm{Hz}$, reactance at $5 \mathrm{~Hz} ; \mathrm{Z}$, impedance of the respiratory system. ${ }^{\star} P<0.05 ; \dagger P<0.001$

Table 5. Spirometry and oscillometry finding in CHF patients before and after treatment with spironolactone.

\begin{tabular}{cccc}
\hline & Before treatment & After treatment & P.Value \\
\hline FEV1 & $2.19 \pm 0.11$ & $2.50 \pm 0.24$ & $\mathbf{0 . 0 6}$ \\
FVC & $2.37 \pm 0.1$ & $2.84 \pm 0.69$ & $\mathbf{0 . 1 8}$ \\
$\mathrm{X}_{5}$ & $-0.14 \pm 0.05$ & $-0.14 \pm 0.05$ & $\mathbf{0 . 9 3}$ \\
$\mathrm{R}_{20}$ & $0.06 \pm 0.06$ & $\mathbf{0 . 3 7}$ \\
$\mathrm{R}_{5}$ & $0.04 \pm 0.03$ & $0.39 \pm 0.15$ & $\mathbf{0 . 3 5}$ \\
$\mathrm{X}_{20}$ & $0.39 \pm 0.21$ & $-0.06 \pm 0.06$ & $\mathbf{0 . 3 7}$ \\
$\mathrm{Zr5}$ & $-0.04 \pm 0.03$ & $0.39 \pm 0.15$ & $\mathbf{0 . 3 5}$ \\
\hline
\end{tabular}

\section{Discussion}

The measurement of the degree of Broncho constriction is normally measured by using forced spirometry. This technique can be even used in patients whom are too weak to perform spirometry, but it also avoids forced maneuvers, which can affect bronchial tone [10] [11]. Impulse oscillometry measures total airway resistance throughout the respiratory cycle, and by altering the frequency of the applied sound wave, allowing localization of the pathology. Also it depends on patient's motivation and respiratory muscle strength lesser than forced maneuvers strongly. Resistance, which was measured by IOS, had a good correlation with assessments of resistance, which measured by the plethysmographic or oesophageal method [11] [12] [13] [14].

The IOS superimposes small air pressure perturbations on the natural breathing of a subject to measure the impedance of the respiratory system. The respiratory Impedance $(\mathrm{Z})$ measured by IOS consists of respiratory Resistance (R) and respiratory Reactance (X). The real part corresponds to the $\mathrm{R}$, which includes the resistance of the proximal and distal airways (central and peripheral), as well as lung tissue and chest wall. Usually, central resistance is dominant, depending on airway caliber and the airway walls surface, while lung tissue and chest wall resistances are usually negligible. In healthy adult subjects, $\mathrm{R}$ is almost independent of oscillation frequency. When an airway obstruction occurs, either 
central or peripheral, $\mathrm{R}_{5}$ (Resistance at $5 \mathrm{~Hz}$ ) is increased above normal values [14] [15].

In our study, the spirometry and oscillometry of CHF patients and controls were evaluated before taking spironolactone and $\mathrm{CHF}$ patients were followed by impulse oscillometry after one month of taking spironolactone. Changes of $\mathrm{FEV}_{1}$ and FVC before taking spironolactone between patients and controls were close to spirometric findings in the study performed by KLAUS and colleagues [15]. While in the study of Klaus R5 and R2O changed more significantly between CHF patients and controls, in comparison to our study in which X5 and R5 changed more between the two groups. After 1 month treatment with spironolactone X5, R5, Zr5, X20, R20 didn't changed significantly. It may be due to short term treatment with spironolactone or small sample size [15] [16].

These findings agree with a recent study performed by Larsen, et al. comparing IOS parameters with spirometry parameters, where it was concluded that the pattern of improvement seen in IOS parameters over the course of therapy, suggest this test might detect alterations in airway mechanics not reflected by spirometry [16].

Our study confirms the presence of abnormalities of pulmonary function in patients with CHF. In this study measurements of the inspiratory and expiratory spirometric parameters $\left(\mathrm{FEV}_{1}(P=0.01)\right.$ and $\left.\mathrm{FVC}(P=0.04)\right)$ were lower in patients than controls, meanwhile IOS parameters $(\mathrm{X} 5(P=0.05)$ and $\mathrm{Z}(P=0.03))$ were significantly greater.

\section{Conclusions}

Because R5 that shows resistances of the peripheral air ways in oscillometry is reduced in patients with heart failure more than control group it seems that spironolactone may decrease the peripheral resistances of airways more than other part of the lung.

Some Limitations of the study were lacking of device in some teaching hospitals and difficult finding control group with old age and without pulmonary disease.

Further more studies in large populations are required to determine the effect of diuretic such as Spironolactone on IOS parameters.

\section{Conflict of Interest}

The author reports no relationships that could be construed as a conflict of interest.

\section{Acknowledgements}

The authors would like to thank Dr. Mohammad Hasan Adel who provided skillful editorial assistance. Financial support for editorial services was provided by Ahwaz Jundishapour research center.

\section{References}

[1] Mc. Cullough, P.A., Nowak, R.M., McCord, J., et al. (2002) B-Type Natriuretic Pep- 
tide and Clinical Judgment in Emergency Diagnosis of Heart Failure: Analysis from Breathing Not Properly (BNP) Multinational Study. Circulation, 106, 416-422. https://doi.org/10.1161/01.CIR.0000025242.79963.4C

[2] Wasserman, K., Zhang, Y.Y., Gitt, A., Belardinelli, R., Koike, A., Lubarsky, L. and Agostoni, P.G. (1997) Lung Function and Exercise Gas Exchange in Chronic Heart Failure. Circulation, 96, 2221-2227. https://doi.org/10.1161/01.CIR.96.7.2221

[3] Witte, K.K. and Clark, A.L. (2005) Beta-Blockers and Inspiratory Pulmonary Function in Chronic Heart Failure. Journal of Cardiac Failure, 11, 112-116. https://doi.org/10.1016/j.cardfail.2004.07.007

[4] Klug, B. and Bisgaard, H. (1998) Specific Airway Resistance, Interrupter Resistance, and Respiratory Impedance in Healthy Children, and Respiratory Impedance in Healthy Children Aged 2 - 7 Years. Pediatric Pulmonology, 25, 322-331. https://doi.org/10.1002/(SICI)1099-0496(199805)25:5<322::AID-PPUL6>3.0.CO;2$\underline{\mathrm{K}}$

[5] Nielsen, K.G. and Bisgaard, H. (2000) The Effect of Inhaled Budesonide on Symptoms, Lung Function, and Cold Air and Methacholine Responsiveness in 2- to 5-Year-Old Asthmatic Children. American Journal of Respiratory and Critical Care Medicine, 162, 1500-1506. https://doi.org/10.1164/ajrccm.162.4.2002019

[6] Gaylor, P.B., Saadeh, C.K., Goldman, M.D., Malacara, J.M. and McGee, M.N. (2003) Forced Oscillation using Impulse Oscillometry (IOS) Provides Objective Responses to Inhaled Corticosteroids (ICS) in Asthmatic Patients When FEV1 Fails to Improve. Journal of Allergy and Clinical Immunology, 111, S135. https://doi.org/10.1016/S0091-6749(03)80423-2

[7] Clark, A.L., Sparrow, J.L. and Coats, A.J.S. (1995) Muscle Fatigue and Dyspnoea in Chronic Heart Failure: Two Sides of the Same Coin? European Heart Journal, 16, 49-52. https://doi.org/10.1093/eurheartj/16.1.49

[8] Wagner, E.M., Bleecker, E.R., Permutt, S. and Liu, M.C. (1992) Peripheral Airways Resistance in Smokers. American Review of Respiratory Disease, 146, 92-95. https://doi.org/10.1164/ajrccm/146.1.92

[9] Nakamura, M., Haga, T., Sasaki, H. and Takishima, T. (1985) Acute Effectsof Cigarette Smoke Inhalation on Peripheral Airways in Dogs. Journal of Applied Physiology, 58, 27-33. https://doi.org/10.1152/jappl.1985.58.1.27

[10] Marotta, A., Klinnert, M.D., Price, M.R., Larsen, G.L. and Liu, A.H. (2003) Impulse Oscillometry Provides an Effective Measure of Lung Dysfunction in 4-Year-Old Children at Risk for Persistent Asthma. Journal of Allergy and Clinical Immunology, 112, 317-321. https://doi.org/10.1067/mai.2003.1627

[11] Nourizadeh, M., Ghelich, Y. and Amin, A. (2013) Study the Mechanical Pulmonary Changes in Patients with Congestive Heart Failure (CHF) by Impulse Oscillometry. Journal of Cardiovascular Disease Research, 2013, 1-4. https://doi.org/10.1016/j.jcdr.2012.06.001

[12] Witte, K.K., Morice, A., Cleland, J.G. and Clark, A.L. (2004) The Reversibility of Increased Airways Resistance in Chronic Heart Failure Measured by Impulse Oscillometry. Journal of Cardiac Failure, 10, 149-154. https://doi.org/10.1016/j.cardfail.2003.08.007

[13] Duiverman, E.J., Clement, J., van de Woestijne, K.P., Neijens, H.J., van den Bergh, A.C. and Kerrebijn, K.F. (2002) Forced Oscillation Technique. Reference Values for Resistance and Reactance. Journal of Cardiac Failure, 8, 2-26.

[14] Meraz, E., Nazeran, H., Ramos, C., Nava, P., Diong, B. and Goldman, M. (2011) Analysis of Impulse Oscillometric Measures of Lung Function and Respiratory Sys- 
tem Model Parameters in Small Airway-Impaired and Healthy Children over a 2-Year Period. BioMedical Engineering OnLine, 10, 43.

[15] Witte, K.K., Morice, A., Clark, A.L. and Cleland, J.G. (2002) Airway Resistance in Chronic Heart Failure Measured by Impulse Oscillometry. Journal of Cardiac Failure, 8, 225-231. https://doi.org/10.1054/jcaf.2002.126916

[16] Larsen, G.L., Morgan, W., Heldt, G.P., et al. (2009) Impulse Oscillometry versus Spirometry in a Long-Term Study of Controller Therapy for Pediatric Asthma. Journal of Allergy and Clinical Immunology, 123, 861-867e1. 